\title{
Characterization of Edible Film Fabricated with Channel Catfish Ictalurus punctatus Gelatin by Cross-Linking with Transglutaminase
}

\author{
Jun-Hyun Oh* \\ Department of Plant and Food Sciences, Sangmyung University, Cheonan 330-720, Korea
}

\begin{abstract}
The objectives of this research were to improve the film-forming properties of Channel Catfish Ictalurus punctatus skin gelatin (CSG) by cross-linking with transglutaminase (TG), determine and optimize the TG reaction time, and characterize the mechanical and barrier properties of CSG edible film. Cross-linking of CSG was performed by TG for $0,10,20,30$, and 40 min at $50^{\circ} \mathrm{C}$, and the reaction was confirmed by sodium dodecyl sulfate-polyacrylamide gel electrophoresis (SDS-PAGE). The color and mechanical and barrier properties of edible films fabricated with CSG cross-linked with TG were characterized. Gelatin yields from the extraction ranged from $18.2 \%$ to $23.3 \%$. SDS-PAGE exhibited dark bands at 120 and $250 \mathrm{kDa}$, indicating successful TG-mediated cross-linking. The color of CSG film was not affected by TG cross-linking. The tensile strength of CSG films cross-linked with TG decreased from 42.59 to $21.73 \mathrm{MPa}$ and the percent elongation increased from $42.92 \%$ to $76.96 \%$ as reaction times increased from 0 to $40 \mathrm{~min}$. There was no significant difference in water vapor permeability of CSG films.
\end{abstract}

Key words: Ictalurus punctatus, Channel catfish, Gelatin, Edible film, Transglutaminase

\section{Introduction}

Gelatin is an important biopolymer and widely used to manufacture gel desserts, edible films in the food industry, and hard and soft capsules in the pharmaceutical industry (Choi and Regenstein, 2000). The principal conventional sources of gelatin are mammalian pig skins and cow hides; however, for a number of reasons, such as religious prohibitions under Judaism and Islam and diseases such as bovine spongiform encephalopathy, alternative sources of gelatin are now in demand (Leuenberger, 1991; Choi and Regenstein, 2000; Montero and Gómez-Guillén, 2000; Sarabia et al., 2000).

Chemical properties of mammalian and fish gelatins differ. Fish gelatins have low gelling and melting temperatures, but relatively high viscosities (Leuenberger, 1991). Researchers have investigated several approaches to alter fish gelatin in an effort to enhance its functionality. Blending of fish gelatin with biopolymers, in conjunction with plasticizers, is one way to improve its properties (Chen et al., 2003; Uresti et al., 2003; Haug et al., 2004). Furthermore, the addition of plasticizers such as glycerol, sorbitol, sucrose, and polyethylene glycol can improve the mechanical properties of fish gelatin films or gels (Tanaka et al., 2001; Vanin et al., 2005). The addition of chemical cross-linking enzymes such as microbial transglutaminase (TG) has also been proven to enhance the properties of fish gelatin (Tseng et al., 1990). Extensive research has focused on the basic characteristics and applications of fish gelatin gels treated with microbial TG (Ramírez et al., 2000; Fernández-Díaz et al., 2001; Uresti et al., 2003; Kolodzlejska et al., 2004).

Farm-raised catfish are important to the economy of small fish farms, and about $55 \%$ of the product of catfish process-
Open Access http://dx.doi.org/10.5657/FAS.2012.0009

This is an Open Access article distributed under the terms of the Creative Commons Attribution Non-Commercial License (http://creativecommons. org/licenses/by-nc/3.0/) which permits unrestricted non-commercial use, distribution, and reproduction in any medium, provided the original work is properly cited. pISSN: 2234-1749 eISSN: 2234-1757
Received 1 November 2011; Revised 12 January 2012; Accepted 8 February 2012

*Corresponding Author

E-mail: junhyunoh@smu.ac.kr 
ing is byproduct that is sold for a low price (Prinyawiwatkul et al., 2002). Therefore, the utilization of catfish byproduct is of great interest and could be beneficial to the catfish farming industry. Therefore, if it is possible to make fabricate gelatin edible films from the gelatin extraction of catfish skins, fish gelatins could be substituted for mammalian gelatins. Although some fish gelatins are currently available commercially, they are not well-characterized. Most studies on gelatin refer to mammalian gelatins, and few studies to fish gelatins have been performed (Leuenberger, 1991; Choi and Regenstein, 2000; Gilsenan and Ross-Murphy, 2000; Montero and Gómez-Guillén, 2000; Sarabia et al., 2000). Therefore, the objectives of this research were to improve the film-forming properties of channel catfish skin gelatin (CSG) extract by cross-linking with TG, determine and optimize the TG reaction time in CSG solution, and characterize the mechanical and barrier properties of CSG edible film.

\section{Materials and Methods}

\section{Cleaning catfish skins and extraction of CSG}

Frozen catfish skins were obtained from Harvest Select Incorporated (Uniontown, AL, USA). Catfish skins were trimmed to remove residual fish meat and fin, cut into small pieces (approximately $20 \times 20 \mathrm{~mm}^{2}$ ), and washed with $4^{\circ} \mathrm{C}$ deionized (DI) water three times. The cleaned fish skins were drained and squeezed by cheesecloth for $5 \mathrm{~min}$ to remove excess water (Zhou and Regenstein, 2004).

Pretreatment procedures were followed by methods previously developed by Zhang et al. (2007). Catfish skin (40 g) was treated with $240 \mathrm{~mL} 0.25 \mathrm{M}$ sodium hydroxide $(\mathrm{NaOH})$ at $4^{\circ} \mathrm{C}$ for $1 \mathrm{~h}$, and then washed with $4^{\circ} \mathrm{C}$ DI water, followed by treatment with $240 \mathrm{~mL} 0.09 \mathrm{M}$ acetic acid at $4^{\circ} \mathrm{C}$ for $1 \mathrm{~h}$. The CSG was extracted with $120 \mathrm{~mL}$ DI water at $50^{\circ} \mathrm{C}$ in a water bath (Isotemp 2L; Thermo Fisher Scientific Inc., Waltham, MA, USA) for $3 \mathrm{~h}$. The mixtures were filtered through glass wool and freeze-dried.

\section{Gelatin yield}

Protein concentrations in CSG extract were determined by the Biuret method by bovine serum albumin as a standard. The gelatin yield, expressed as protein yield, was calculated as follows (Zhou and Regenstein, 2004):

Protein yield $(\%)=($ protein concentration $[\mathrm{g} / \mathrm{mL}] \times$ volume of extract $[\mathrm{mL} /$ weight of catfish skin $(\mathrm{g})]) \times 100$.

\section{Preparation of enzymatic cross-linked CSG solution}

CSG solution was prepared by mixing $18 \mathrm{~g}$ gelatin (3\% gelatin) and $5.4 \mathrm{~g}$ glycerol (30\% glycerol based on gelatin con- tent) in $600 \mathrm{~mL}$ DI water. The solute was dissolved at $50^{\circ} \mathrm{C}$ for $1 \mathrm{~h}$. After dissolving, $0.1 \mathrm{M} \mathrm{NaOH}$ was added until the $\mathrm{pH}$ reached approximately 7.0. The solution was then centrifuged at $5,000 \mathrm{~g}$ for $10 \mathrm{~min}$ at $25^{\circ} \mathrm{C}$. After centrifugation, the solution was kept in a water bath (Isotemp 2L; Thermo Fisher Scientific Inc.) at $50^{\circ} \mathrm{C}$ until use.

TG (Ajinomoto ACTIVA T1) was purchased from Ajinomoto Food Ingredients LLC (Paramus, NJ, USA). The enzyme consisted of $99 \%$ lactose and $1 \%$ TG according to the manufacturer's specifications. TG powder $(1,200 \mathrm{mg})$ was dissolved in $15 \mathrm{~mL}$ DI water and mixed by a Touch Mixer (Vortex Mixer; Thermo Fisher Scientific Inc.) The TG solution was centrifuged at $5,000 \mathrm{~g}$ for $15 \mathrm{~min}$ at $0^{\circ} \mathrm{C}$ by a Sorvall $\mathrm{RC}$ 5B Plus centrifuge (Kendro Laboratory Products, Asheville, NC, USA). After centrifugation, the supernatant was removed. The pellets were obtained and added to $15 \mathrm{~mL}$ DI water. The TG solution (1,200 mg in $15 \mathrm{~mL}$ water) was then added to the gelatin solution. This was then aliquoted into 5 beakers, which corresponded to reaction times of $0,10,20,30$, and $40 \mathrm{~min}$ in a water bath (Isotemp 2L; Thermo Fisher Scientific Inc.) at $50^{\circ} \mathrm{C}$. TG deactivation was accomplished by boiling for $5 \mathrm{~min}$.

\section{Fabrication of CSG film cross-linked with TG}

For the film-forming solutions, 1\% gelatin and 20\% glycerol contents were selected based on previous reports (Sobral et al., 2001; Jongjareonrak et al., 2006). After TG deactivation, TG-treated gelatin solutions were poured onto a BYTAC type VF-81 FEP (SPI Supplies/Structure Probe, Inc., West Chester, PA, USA) coated glass plate $\left(25 \times 25 \mathrm{~cm}^{2}\right)$. The plates were balanced before adding the gelatin mixture to ensure even distribution of film solution. During pouring, the solutions were filtered through 2 layers of cheesecloth to remove impurities and bubbles. The poured solutions were dried at room temperature (approximately $25^{\circ} \mathrm{C}$ ) for $24 \mathrm{~h}$. The film was checked after $12 \mathrm{~h}$ to ensure that conditions were favorable for the production of a good film. Dried films were then carefully removed from the plates (Zhang et al., 2007).

\section{Sodium dodecyl sulfate-polyacrylamide gel elec- trophoresis}

Sodium dodecyl sulfate-polyacrylamide gel electrophoresis (SDS-PAGE) was performed with a Ready Gel Precast Gel System (Bio-Rad Laboratories, Inc., Hercules, CA, USA) to determine the molecular weight (MW) profile of the CSG extracts (Laemmli, 1970). A pre-cast 4\% stacking gel and $10-20 \%$ continuous gradient separating gels (Sigma-Aldrich Chemical Co., St. Louis, MO, USA) were used. After measuring the protein concentrations, the gelatin extracts were diluted to approximately $1.0 \mathrm{mg} / \mathrm{mL}$ with $62.5 \mathrm{mM}$ Tris buffer and boiled for $3 \mathrm{~min}$ in a water bath (Isotemp 2L; Thermo Fisher Scientific Inc.). An aliquot $(15 \mu \mathrm{L})$ from each CSG diluent was loaded onto the stacking gel. The PageRuler Prestained 
Protein Ladder Plus molecular weight marker mix (Fermentas, Hanover, MD, USA) with MW from 10 to $250 \mathrm{kDa}$ was used as a standard. An electrical field of 0.4 volt $/ \mathrm{mm}$ was applied to the gel, and increased to $0.75 \mathrm{volt} / \mathrm{mm}$ once the dye fronts reached the separating gel (Zhang et al., 2007).

\section{Determination of gelatin film color}

The Hunter color scale of lightness (L), redness (a), and yellowness (b) of catfish films was determined by a CR-300 Minolta Chromameter (Minolta Camera Co., Osaka, Japan). The light source was illuminant $\mathrm{C}$, and the white plate (CR$\mathrm{A} 43 ; \mathrm{L}=96.86, \mathrm{a}=-0.02$, and $\mathrm{b}=1.99$ ) provided by the manufacturer was used for calibration and background.

\section{Mechanical properties}

Tensile strength (TS) and percent elongation (\%E) of CSG films were determined by following the standard procedures of ASTM D 882-97 (American Society for Testing and Materials 1998) by a Mini-44 Instron (Instron Co., Canton, MA, USA). The CSG films conditioned in an environmental chamber (Model 435314; Hotpack Corp., Philadelphia, PA, USA) at $25^{\circ} \mathrm{C}$ and $50 \%$ relative humidity for $16 \mathrm{~h}$ were cut into $20 \times$ $50 \mathrm{~mm}^{2}$ strips, and the thickness of each strip at three locations (top, center, and bottom) was measured and recorded by a hand-held electronic digital micrometer (CO030150F6; Marathon Watch Company, Ltd., Richmond Hill, ON, Canada). The mean of the three thickness measurements of each strip was used to calculate TS and \%E of the film. Each strip was fastened onto screw-action grips with an initial $20 \mathrm{~mm}$ gap (the distance between the top and bottom grip), and the strip was stretched using the grips at a head speed of $50 \mathrm{~mm} / \mathrm{min}$ until broken. The TS of CSG films was calculated as follows:

$\mathrm{TS}=$ peak load $(\mathrm{N}) /$ initial cross-sectional area $\left(\mathrm{m}^{2}\right)$.

$\%$ E was calculated as follows:

$\% \mathrm{E}=$ final gap $(\mathrm{mm}) /$ initial gap $(\mathrm{mm}) \times 100$.

\section{Water vapor permeability}

Water vapor permeability (WVP) was determined following the ASTM E96-95 standard method (American Society for Testing and Materials 1999) using Fisher permeability cups (Thermo Fisher Scientific Inc.). The CSG films were cut into 55-mm-diameter circles, and their thickness was measured at five locations in the circle (top, bottom, left, and right $10 \mathrm{~mm}$ from the edge and center). The mean film thickness was used to calculate WVP. Each circle was mounted on the test cell and tightly fastened with the top cover. A thin layer of silicone high-vacuum grease (Dow Corning, Midland, MI, USA) was used as a sealant to avoid vapor leaks through cup joints. After measuring the initial weight, the test cups were placed in an environmental chamber (Model 435314; Hotpack Corp.) at $25^{\circ} \mathrm{C}$ and $50 \%$ relative humidity for $24 \mathrm{~h}$, and weight changes were recorded. The WVP of the films was calculated as follows:

$\operatorname{WVP}(\mathrm{g} / \mathrm{Pa} / \mathrm{s} / \mathrm{m})=$ water permeance $\left(\mathrm{g} / \mathrm{Pa} / \mathrm{s} / \mathrm{m}^{2}\right) \times$ thickness $(\mathrm{m})$,

where water permeance $=\mathrm{WVT} / \Delta \mathrm{P}, \mathrm{WVT}=$ weight change $/$ (time $[\mathrm{h}] \times$ area $\left[\mathrm{m}^{2}\right]$ ), and $\Delta \mathrm{P}=$ vapor pressure differences across the film ( $\mathrm{mm} \mathrm{Hg}$ ).

\section{Statistical analysis}

Each experiment was repeated six times. One way analysis of variance (ANOVA) was performed using the SPSS version 11.5 (SPSS Inc., Chicago, IL, USA). The differences among means were analyzed using least significant difference, and the significance level was defined as $P<0.05$.

\section{Results and Discussion}

\section{Gelatin yield}

The gelatin yields expressed as protein yield from the extraction method ranged from $18.2 \%$ to $23.3 \%$. The gelatin yield extracted from Alaskan pollock skin using a pretreatment method similar to ours was approximately 18\% (Zhou and Regenstein, 2004). Gudmundsson and Hafsteinsson (1997) also obtained gelatin yields of 11-14\% from cod skin using a similar pretreatment method.

\section{SDS-PAGE}

The molecular mass profile of the gelatin films produced in the presence of TG (Fig. 1). The band profiles of SDS-PAGE at 0 min exhibited a typical CSG band profile, two darker bands at $\sim 120$ and $\sim 250 \mathrm{kDa}$ (Lane 1) (Zhang et al., 2007). According to Zhou and Regenstein (2004), the $250 \mathrm{kDa}$ band is the $\beta$-chain of collagen and that at $120 \mathrm{kDa}$ is the $\alpha$-chain. The introduction of TG to the film solutions resulted in the formation of high molecular mass polymers, exhibiting a much darker band at $250 \mathrm{kDa}$ (lanes 2-5). As the TG reaction time increased from 10 to $40 \mathrm{~min}$, more collagen $\beta$-chain was formed by TG. These results indicate that TG cross-linked the fish gelatin matrix, forming higher-molecular-weight fish gelatins.

Similar results were reported for megrim skin and mammal gelatins (Lim et al., 1999; Gómez-Guillén and Montero, 2001; Yi et al., 2006). The authors observed decreasing band intensity at $\sim 100 \mathrm{kDa}$ and increasing band intensity in the upper part of the gel when the gelatin was treated with TG. Ramírez et al. (2002) reported the same in fish proteins, such as myosin, due to TG-induced cross-linking. 


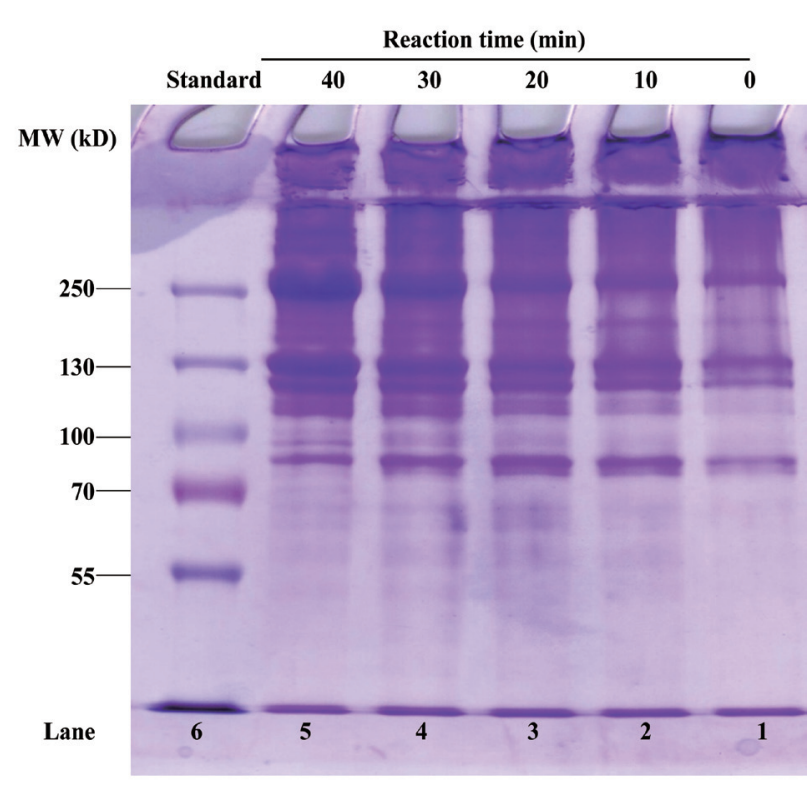

Fig. 1. Representative sodium dodecyl sulfate-polyacrylamide gel electrophoresis (SDS-PAGE) profile of channel catfish Ictalurus punctatus gelatin extracted using selected reaction times from 0 to $40 \mathrm{~min}$. Lane numbers of 1, 2, 3, 4, 5, and 6 indicate the SDS-PAGE bands of 0 min, $10 \mathrm{~min}-, 20 \mathrm{~min}-, 30 \mathrm{~min}-$, and 40 min-reaction time, and standard, respectively.

\section{Color}

The lightness (L), redness (a), and yellowness (b) of the CSG films were not significantly affected by either TG crosslinking or reaction time (Table 1). Yi et al. (2006) reported that the L of films cross-linked with TG was not significantly affected by reaction time, in agreement with our observation. However, they observed that the red/green (a) and yellow/blue (b) values varied from $-0.19 \pm 0.01$ to $-0.23 \pm 0.00$ and 3.36 \pm 0.06 to $3.47 \pm 0.09$, respectively, indicating that films became more greenish with time. No significant difference in the color of catfish films cross-linked with TG was observed in this study, presumably due to our use of a different type of fish gelatin.

Table 1. Effect of reaction time of transglutaminase on color of channel catfish Ictalurus punctatus gelatin films

\begin{tabular}{cccc}
\hline \multirow{2}{*}{$\begin{array}{c}\text { Reaction time } \\
(\text { min) }\end{array}$} & \multicolumn{3}{c}{ Color } \\
\cline { 2 - 4 } & $\mathbf{L}$ & $\mathbf{a}$ & $\mathbf{b}$ \\
\hline 0 & $98.77 \pm 0.08^{\mathrm{a}^{*}}$ & $0.01 \pm 0.01^{\mathrm{a}}$ & $2.20 \pm 0.01^{\mathrm{a}}$ \\
10 & $98.72 \pm 0.07^{\mathrm{a}}$ & $-0.02 \pm 0.01^{\mathrm{a}}$ & $2.21 \pm 0.01^{\mathrm{a}}$ \\
20 & $98.85 \pm 0.07^{\mathrm{a}}$ & $-0.01 \pm 0.01^{\mathrm{a}}$ & $2.20 \pm 0.03^{\mathrm{a}}$ \\
30 & $98.77 \pm 0.05^{\mathrm{a}}$ & $-0.02 \pm 0.01^{\mathrm{a}}$ & $2.25 \pm 0.02^{\mathrm{a}}$ \\
40 & $98.85 \pm 0.07^{\mathrm{a}}$ & $-0.02 \pm 0.01^{\mathrm{a}}$ & $2.24 \pm 0.03^{\mathrm{a}}$ \\
\hline
\end{tabular}

The superscript letters within the columns indicate significant differences between the means obtained by one-way ANOVA test $(P<0.05)$.

L, lightness; a, redness; $b$, yellowness.

\section{Mechanical properties of CSG film cross-linked with TG}

CSG films cross-linked with TG ranged from $0.046 \pm$ 0.0009 to $0.0493 \pm 0.0018 \mathrm{~mm}$ thick. These values were used to calculate the TS and $\% \mathrm{E}$ of the films. In general, gelatin films possess greater TS than that of other protein films, such as casein or whey films (Chambi and Grosso, 2006). This was related to the organizational level of the protein network. Gelatin possesses a relatively disorganized structure, but it can renature during the gelling and film-forming process, partially reacquiring the collagen triple helix structure, a protein with a high degree of organization (Achet and He, 1995). According to Siew et al. (1999), the increase in chain organization likely optimizes molecular packing, resulting in films with desirable mechanical and barrier properties.

A decrease in TS and simultaneous increase in $\% \mathrm{E}$ is a characteristic property of other protein or polysaccharide films plasticized with different hydrophilic compounds (Arvanitoyannis and Biliaderis, 1998; Tanaka et al., 2001). The introduction of plasticizers into the polymeric matrix also results in higher $\%$ E values. Plasticizers decrease intermolecular attractive forces and increase biopolymer chain mobility; as a result, film flexibility and extensibility can be improved (Gennadios and Weller, 1990). The CSG films that cross-linked with TG and which contained $20 \%$ glycerol as a plasticizer exhibited lower TS and higher \%E values (Park et al., 2008).

The effects of TG cross-linking on the mechanical properties of gelatin films remain to be resolved. With respect to TG treatment, the introduction of cross-linkages did not result in significant changes in TS compared to untreated films (Chambi and Grosso, 2006). Oh et al. (2004) and de Carvalho and Grosso (2004) obtained similar results for milk protein and type B gelatin films cross-linked with TG. Babin and Dickinson (2001) observed that treatment with TG could result in both positive and negative results with respect to the strength of gelatin films. Also, Yi et al. (2006) reported that the TS of cross-linked fish gelatin films increased from 48.03 to 68.00 $\mathrm{MPa}$ and that the $\% \mathrm{E}$ decreased from 13.1 to $1.47 \%$, as reaction time increased from 0 to $50 \mathrm{~min}$.

However, our data suggest that the TS of CSG films crosslinked with TG decreased from 42.59 to $21.73 \mathrm{MPa}$ and that the $\% \mathrm{E}$ increased from $42.92 \%$ to $76.96 \%$ as the reaction time increased from 0 to $40 \mathrm{~min}$ (Fig. 2). These results are in good agreement with those of other investigators. Lim et al. (1999) reported that the TS of gelatin films were comparable to those of other protein films. Although direct comparison between samples was unreliable due to varying test conditions and substrates, the TG cross-linked gelatin films exhibited much higher \%E values (Lim et al., 1999). Films produced by TG had higher \%E values than those that did not use TG (Chambi and Grosso, 2006). Daniels (1989) speculated that cross-linking of gelatin by TG could increase $\% \mathrm{E}$ because the structure of the overall materials shifts from that of individual chains associ- 


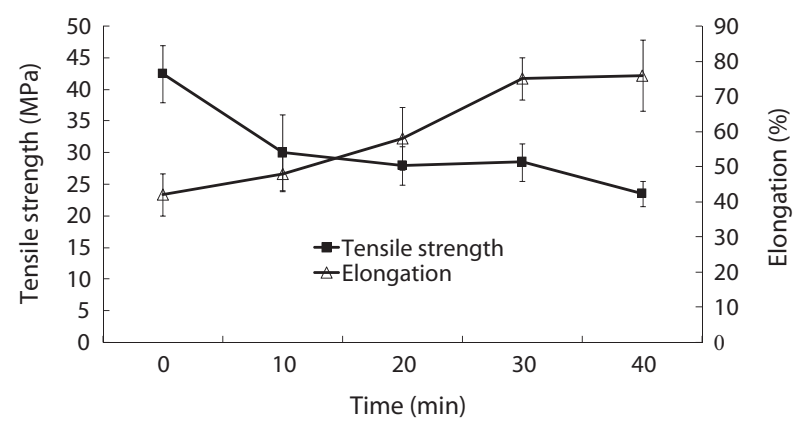

Fig. 2. Effect of cross-linking with reaction time of transglutaminase on the tensile strength and percent elongation of channel catfish Ictalurus punctatus gelatin film.

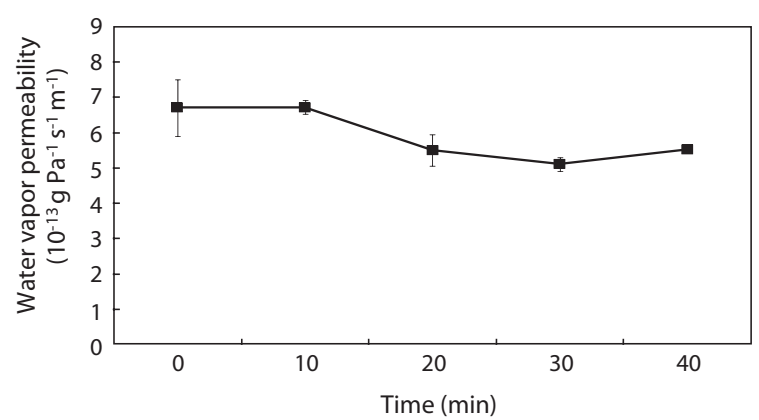

Fig. 3. Water vapor permeability of channel catfish Ictalurus punctatus gelatin films cross-linked with reaction time of transglutaminase.

ated with many weak van der Waals forces, to chains bound by a few, but strong, covalent bonds.

\section{WVP of CSG film cross-linked with TG}

The WVP values of CSG films ranged from 5.19 to 6.82 $\times 10^{-13} \mathrm{~g} \mathrm{~Pa}^{-1} \mathrm{~s}^{-1} \mathrm{~m}^{-1}$ (Fig. 3). WVP exhibited no significant differences as TG reaction time increased. These results are in agreement with other reports. Although de Carvalho and Grosso (2004) reported that the WVP coefficient was lower in bovine gelatin films cross-linked with TG than in an untreated gelatin film, Piotrowska et al. (2008) observed that the water barrier properties of fish skin gelatin were not altered by TG cross-linking.

Addition of glycerol to film solutions usually worsens the water barrier properties of polysaccharide or protein films (Butler et al., 1996; Arvanitoyannis et al., 1998). Here we used glycerol, which may explain the low WVP values compared to other films. Yi et al. (2006) observed that WVP was ont affected by TG reaction time, which may have been due to the effect of the plasticizer. The authors found that addition of a hydrophilic plasticizer, favoring the adsorption and desorption of water molecules, improved the WVP of hydrocolloidbased films. The film to which $20 \%$ D-sorbitol was added as a plasticizer exhibited an increased WVP due to its hydrophilic activity, thus masking the effect of TG-induced cross-linking.

In conclusion, upon TG cross-linking, the molecular mass profile of gelatin films increased with reaction time. The TG cross-linking reaction did not affect the color of the films. However, cross-linking resulted in a significant decrease in $\mathrm{TS}$, and a significant increase in $\% \mathrm{E}$, with increasing reaction time. Therefore, cross-linking of CSG with TG may improve the flexibility of gelatin films without affecting its barrier properties. Further research on the potential application of TG to fish gelatin films in the food and pharmaceutical industries is now necessary.

\section{Acknowledgments}

This research project was funded by the Sangmyung University Research Fund (2010-A000-0153).

\section{References}

Achet D and He XW. 1995. Determination of the renaturation level in gelatin films. Polymer 36, 787-791.

Arvanitoyannis I and Biliaderis CG. 1998. Physical properties of polyolplasticized edible films made from sodium caseinate and soluble starch blends. Food Chem 62, 333-342.

Arvanitoyannis IS, Nakayama A and Aiba S. 1998. Chitosan and gelatin based edible films: state diagrams, mechanical and permeation properties. Carbohydr Polym 37, 371-382.

American Society for Testing and Materials. 1998. Standard Test Method for Tensile Properties of Thin Plastic Sheeting. D 882-97. ASTM, Philadelphia, PA, US.

American Society for Testing and Materials. 1999. Standard Test Method for Water Vapor Transmission of Materials. E 96-95. ASTM, Philadelphia, PA, US.

Babin H and Dickinson E. 2001. Influence of transglutaminase treatment on the thermoreversible gelation of gelatin. Food Hydrocoll 15, 271-276.

Butler BL, Vergano PJ, Testin RF, Bunn JM and Wiles JL. 1996. Mechanical and barrier properties of edible chitosan films as affected by composition and storage. J Food Sci 61, 953-956.

Chambi H and Grosso C. 2006. Edible films produced with gelatin and casein cross-linked with transglutaminase. Food Res Int 39, 458466.

Chen T, Embree H, Brown EM, Taylor MM and Payne GF. 2003. Enzyme-catalyzed gel formation of gelatin and chitosan: potential for in situ applications. Biomaterials 24, 2831-2841.

Choi SS and Regenstein JM. 2000. Physicochemical and sensory characteristics of fish gelatin. J Food Sci 65, 194-199.

Daniels CA. 1989. Polymers: Structure and Properties. Technomic Publishing Company Inc., Lanchester, PA, US.

de Carvalho RA and Grosso CRF. 2004. Characterization of gelatin based films modified with transglutaminase, glyoxal and formaldehyde. Food Hydrocoll 18, 717-726. 
Fernández-Díaz MD, Montero P and Gómez-Guillén MC. 2001. Gel properties of collagens from skins of cod (Gadus morhua) and hake (Merluccius merluccius) and their modification by the coenhancers magnesium sulphate, glycerol and transglutaminase. Food Chem 74, 161-167.

Gennadios A and Weller CL. 1990. Edible films and coatings from wheat and corn proteins. Food Technol 44, 63-69.

Gilsenan PM and Ross-Murphy SB. 2000. Viscoelasticity and thermoreversible gelatin gels from mammalian and piscine collagens. J Rheol 44, 871-883.

Gómez-Guillén MC and Montero P. 2001. Extraction of gelatin from megrim (Lepidorhombus boscii) skins with several organic acids. J Food Sci 66, 213-216.

Gudmundsson M and Hafsteinsson H. 1997. Gelatin from cod skins as affected by chemical treatment. J Food Sci 62, 37-39.

Haug IJ, Draget KI and Smidrød O. 2004. Physical behavior of fish gelatin-kappa-carrageenan mixtures. Carbohydr Polym 56, 11-19.

Jongjareonrak A, Benjakul S, Visessanguan W, Prodpran T and Tanaka M. 2006. Characterization of edible films from skin gelatin of brownstripe red snapper and bigeye snapper. Food Hydrocoll 20, 492-501.

Kolodzlejska I, Kaczorowski K, Piotrowska B and Sadowska M. 2004. Modification of the properties of gelatin from skins of Baltic cod (Gadus morhua) with transglutaminase. Food Chem 86, 203-209.

Laemmli UK. 1970. Cleavage of structural proteins during the assembly of the head of bacteriophage T4. Nature 227, 680-685.

Leuenberger BH. 1991. Investigation of viscosity and gelation properties of different mammalian and fish gelatins. Food Hydrocoll 5, 353-361.

Lim LT, Mine Y and Tung MA. 1999. Barrier and tensile properties of transglutaminase cross-linked gelatin films as affected by relative humidity, temperature, and glycerol content. J Food Sci 64 , 616-622.

Montero P and Gómez-Guillén MC. 2000. Extraction conditions for megrim (Lepidorhombus boscii) skin collagen affect functional properties of the resulting gelatin. J Food Sci 65, 434-438.

Oh JH, Wang B, Field PD and Aglan HA. 2004. Characteristics of edible films made from dairy proteins and zein hydrolysate cross-linked with transglutaminase. Int J Food Sci Technol 39, 287-294.

Park JW, Whiteside WS and Cho SY. 2008. Mechanical and water vapor barrier properties of extruded and heat-pressed gelatin films. LWT Food Sci Technol 41, 692-700.

Piotrowska B, Sztuka K, Kołodziejska I and Dobrosielska E. 2008. Influence of transglutaminase or 1-ethyl-3-(3-dimethylaminopropyl) carbodiimide (EDC) on the properties of fish-skin gelatin films. Food Hydrocoll 22, 1362-1371.

Prinyawiwatkul W, Suvanich V, Harrison RW, King JM, Sathivel S, Pacheco K, Rout SK, Nadarajah K and Sonti S. 2002. Value-added crawfish and catfish. Louisiana Agric 45, 20-21.

Ramírez JA, Rodríguez-Sosa R, Morales OG and Vázquez M. 2000. Surimi gels from striped mullet (Mugil cephalus) employing microbial transglutaminase. Food Chem 70, 443-449.

Ramírez J, Uresti R, Téllez S and Vázquez M. 2002. Using salt and microbial transglutaminase as binding agents in restructured fish products resembling hams. J Food Sci 67, 1778-1784.

Sarabia AI, Gómez-Guillén MC and Montero P. 2000. The effect of added salts on the viscoelastic properties of fish skin gelatin. Food Chem 70, 71-76.

Siew DC, Heilmann C, Easteal AJ and Cooney RP. 1999. Solution and film properties of sodium caseinate/glycerol and sodium caseinate/ polyethylene glycol edible coating systems. J Agric Food Chem 47, 3432-3440.

Sobral PJA, Menegalli FC, Hubinger MD and Roques MA. 2001. Mechanical, water vapor barrier and thermal properties of gelatin based edible films. Food Hydrocoll 15, 423-432.

Tanaka M, Ishizaki S, Suzuki T and Takai R. 2001. Water vapor permeability of edible films prepared from fish water soluble proteins as affected by lipid type. J Tokyo Univ Fish 87, 31-37.

Tseng YC, Tabata Y, Hyon SH and Ikada Y. 1990. In vitro toxicity test of 2-cyanoacrylate polymers by cell culture method. J Biomed Mater Res 24, 1355-1367.

Uresti RM, Ramirez JA, López-Arias N and Vázquez M. 2003. Negative effect of combining microbial transglutaminase with low methoxyl pectins on the mechanical properties and colour attributes of fish gels. Food Chem 80, 551-556.

Vanin FM, Sobral PJA, Menegalli FC, Carvalho RA and Habitante AMQB. 2005. Effects of plasticizers and their concentrations on thermal and functional properties of gelatin-based films. Food Hydrocoll 19, 899-907.

Yi JB, Kim YT, Bae HJ, Whiteside WS and Park HJ. 2006. Influence of transglutaminase-induced cross-linking on properties of fish gelatin films. J Food Sci 71, E376-E383.

Zhang S, Wang Y, Herring JL and Oh JH. 2007. Characterization of edible film fabricated with channel catfish (Ictalurus punctatus) gelatin extract using selected pretreatment methods. J Food Sci 72, C498-C503.

Zhou P and Regenstein JM. 2004. Optimization of extraction conditions for pollock skin gelatin. J Food Sci 69, C393-C398. 